\title{
The right to energy: meaning, specification and the politics of definition
}

\author{
Professor Gordon Walker, DEMAND Centre, Lancaster University
}

\section{Introduction}

Talking about 'rights' has become a pervasive political framing and discourse 'rights inhabit our ordinary moral and political thinking' (Jones 1994). Rights-talk constitutes a mode of claim-making about what should be in place and protected for individuals (or groups) and, it often follows, about what duties and obligations should rest with others and in particular the State, to provide for and protect these rights. The right to energy is a relatively recent addition to 'rights-talk' with examples ranging across scales and national contexts. For some campaigners it has been used as a way of making political demands of national governments and their social regulation of and intervention in the energy system, an example being the UK campaign for an 'Energy Bill of Rights' (Fuel Poverty Action 2015). For others the right to energy has been seen as a prime candidate for entry into the international United Nations human rights framework, taking its place alongside other 'second generation' socio-economic rights such as the right to water, shelter and food, as a basic necessity for all people. For example, the international non-governmental organisation Droit a L'Energie-SOS Future (Right to Energy SOS Future) founded in 2000 and with a membership of 401 organisations from 68 countries, states as its first objective 'to assemble all those wishing to act for the recognition of the right to energy as a basic human right, for the sharing of energy resources and for the protection of the global environment'. Freling (2012) similarly argues for a formal and explicit recognition of the right to energy:

"Energy is essential for life. It is essential for achieving the Millennium Development Goals. And it is essential for safeguarding a broad range of basic human rights. The right of access to energy is, in fact, implicitly conferred by a number of international treaties and conventions, but now the time has come to make such an assumption explicit and formally declare-with the full backing and authority of the United Nations - that access to modern energy is, and shall henceforth be deemed, a basic human right"

The need to extend rights of access to energy in developing countries has also been enrolled into debates about responses to climate change, with Sen (2014) for example arguing that: 
'In thinking about human freedom today and sustaining it in the future, we have to take fuller note of the need for greater energy use for a large number of deprived people in the world .... The focus has to be shifted from single-minded concentration on reducing emissions to a broader understanding of the range of needs of people and the demands that come from expanding and sustaining freedoms to live reasonably good lives' (Sen 2014)

Whilst such arguments are immediately compelling, and using a rights language has considerable rhetorical force, it is important to consider carefully what is involved in moving from the broad notion of any right through to its meaning, specification and implementation in practice, as well to evaluate the range of arguments that have been made against a reliance on rights declarations as a means of achieving social progress and pursuing justice oriented objectives. As Jones (1994) argues, rights-talk is easy with the consequence that "the popularity of rights has been achieved at a price. If an idea is promiscuously available to all, it will find itself pressed into every sort of interest, cause or persuasion". Attoh (2011) is also clear that "the practical significance of rights depends both on how we define a right and on the specific form a given right takes", with questions of definition and specification often becoming matters of intense political debate and contestation, even if the broad notion of a right is widely supported.

In this paper I particularly consider questions of meaning and specification, problematizing the outwardly simple formulation of a 'right to energy' and examining in what terms the notion of a universal right might be sustained. My objective is to characterise the space for political work focused on defining the right to energy, its specification and implementation, bringing forward a set of questions which have are typically under-examined. In taking forward this discussion I am particularly concerned with recognising the differing roles that the use of energy plays in enabling well-being and capabilities (Walker 2013) across varied, situated contexts internationally and regionally. Whilst questions of diversity and variation in 'what energy is for' are clearly globally important, they are just as relevant in a European context (Bafoil et al. 2014), particularly given the enduring tensions between adopting common and harmonised policies across the European Union, and enabling degrees of subsidiarity which are more open to nation-state determination.

I begin my discussion by considering energy and energy services as concepts which immediately complicate the specification of a right to energy. I then consider alternative ways of thinking about first the right to access energy and second the right to be able to use energy. Here I use examples from the UK, a country in which questions of fuel poverty have had a high political profile for some time and 
policies focused on addressing inequalities in the affordability of energy are relatively well developed (Boardman 2010, Walker and Day 2012, Hills 2012, Christman and Russell 2015). In concluding I argue that whilst opening up the meaning and specification of the right to energy introduces complexities that might be seen to challenge both it's value and potential universality, this is crucial territory for ongoing debates about the interaction between energy poverty and climate justice objectives.

\section{Energy and energy services as involved concepts}

When faced with giving meaning to the right to energy, 'energy' is the obvious starting point. Energy is far from a straightforward term, having multiple meanings in both its everyday and more technical uses. Illich (1983) argues that energy is a 'verbal symbol' with a 'collage of meanings', without a simple, immediate and singular form. The notion of energy as a resource, which can be accessed and consumed in some way (commercially or outside of systems of exchange), categorises together many different forms of material substance and energetic flow, which through an analytical understanding embedded in physics, contain a demonstrable and measurable potentiality for transformation into useful energy services. This 'energy as useful resource' category is enormously diverse, including for example wood, coal, oil, propane, wind, gas, moving water, solar radiation and many others. So when the right to energy is deployed the immediate question is 'to what form(s) of energy'? Any and all forms, or are some to be valued more than others and some excluded whilst others are prioritised?

Some advocacy and analysis has specifically focused on the right to electricity (Tully 2006), giving this energy form a particularly important status due to what it enables that other energy forms cannot (e.g. powering computers, mobile phones and so on) and its 'cleanliness', at least at point of use. Along similar lines but less immediately constrained, most preliminary specifications of the right to energy usually apply descriptive qualifiers, such as 'clean', 'modern' or 'sustainable' therefore looking for particular qualities in the energy there is a right to, but leaving the application of these qualifiers to later determination. Clearly much can rest on the interpretation of such terms, what is 'modern' now may not be in 20 years time; what is considered 'sustainable' under one interpretation or under one set of conditions, may not be in another. The ambivalent status of biomass and biofuels as sustainable, modern or clean energy forms is a good example of where much depends on the conditions and contexts of use, generating considerable technical debate and political disagreement. 
Taking a step further towards thinking about why 'energy' is really valued and seen as a basic necessity, necessarily turns attention towards the 'energy services' that are derived from the consumption of energy resources. Energy as such is not what is important. It is rather the heat, cool, light, mobility, communication, cooking of food and other services that energy provides which contribute to well-being, and to being able to achieve a range of basic capabilities (Walker 2013). The demand for energy is a derived demand and matters normatively because of what energy is used for, what it can be used to achieve (Shove and Walker 2014). Does it therefore make sense that the right to energy is then reformulated in terms of the right to energy services (Bradbrook and Gardam 2006), given that it is these which really provide value to human flourishing? For example in the UK there is a long standing campaign for the 'right to warmth' (see www.rightstowarmth.org.uk), focused on fuel poverty but articulating this in terms of a key energy service - heat or warmth - rather than energy or fuel. One of the arguments for this approach is that it recognises that warmth can be achieved and enhanced in a range of different ways, not just through using energy for heating (which can involve many different forms of energy resource), but also through having a well-insulated building and maximising the use of 'natural heat' from the sun.

Well there is much logical sense in de-centring energy in this way, any such move immediately raises the question of what energy services matter to the degree that they should meaningfully become the focus of rights claims. This is it not just a matter of political or cultural evaluation, as there is a strong geographical dependency to energy 'needs' related to the variability of climatic conditions across the world. Whilst the 'right to warmth' might be seen as a key energy service in the UK, in Taiwan or Singapore this would make little sense, with climatic conditions meaning that cooling would be seen as a far more relevant and important energy service than warmth. For some countries this geographic variability is to be found within national boundaries. Chile, for example, stretches across quite different climatic zones with very different needs for heating and cooling as a consequence across its territory. Across the European Union as a regional governance unit the same degree of variation very much applies between Northern and Southern European climatic conditions. There is also distinct variability for the relationship between natural and artificial light, with patterns of daylight length and intensity very differentiated across space and time. Whilst arguably other forms of energy service - such as computational capacity and communication enabled by electricity - have a more constant relevance to quality of life, it is clear that the idea of the right to energy services being simply definable in universal and global terms is problematic. 
All rights to some degree have degrees of complexity in their definition, and there is a danger in overplaying the difficulties of specification as a reason for dismissing the value of rights declarations. In some terms though, the right to energy is more complex in its meaning and definition than other comparable rights. The right to water has generated much debate about definition and implementation (Bakker 2007, Sultana and Loftus 2013, Joy et al. 2014), but does focus attention on one key substance with a clear material definition $\left(\mathrm{H}_{2} \mathrm{O}\right)$. Quality clearly matters, given that to be of value to well-being water needs to have a certain level of purity, but possibilities to satisfy the right are not opened up across a diversity of material forms as is the case with energy. Water also has one crucial central value to human existence, applicable to all people everywhere and that is truly universal. Water has other important subsidiary uses in addition to drinking (such as cleanliness), but unlike energy it there is at least one undisputed and constant relation to individual well-being. Energy is therefore a fundamentally more complex resource category than water, but other socioeconomic rights are arguably just as difficult to define and specify, with the right to shelter, for example, raising a similar range and depth of basic questions about meaning, value and form.

\section{The right to have access or the right to be able to use?}

It is clear from the discussion to this point that basic questions of definition constitute a substantial space for political work over what the right to energy should mean. Challenges to the possibility of universality in meaning have also been identified. Further questions of specification then arise over how far the right to energy should extend in terms of the interface between energy supply and demand. Should it be just a matter of putting supply infrastructure in place (the right to have access) or should it extend to ensuring that the demand for energy that is needed to sustain basic levels of well-being can be realised by all citizens (the right to be able to use)? Considering this distinction raises potentially contentious additional details of how any right to energy should be understood and implemented.

The right to energy is often discussed and evaluated through a language of access. When applied specifically to electricity this has been understood in terms of 'connection' and measured through indicators of proportions of households connected to an electricity grid - although recent developments in distributed micro-generation have challenged expectations that electricity supply infrastructure need take the form of a conventional large-scale grid. As stressed earlier though energy can take different 
forms and whilst electricity is often seen as a 'superior' form of energy, this does not preclude the importance of enabling access to other energy forms of energy infrastructure and distribution system. In any one setting there can multiple infrastructural forms potentially available to satisfy a right to energy, and it is a matter of political resolution as to which are to be enabled as 'universal'. For example, in the UK as shown in Table 1, there is an estimated $100 \%$ connection of domestic properties to the electricity grid, and rules that apply to new grid connections are intended to compel distribution companies to install the necessary infrastructure, subject only to the charging of 'reasonable expenses'. In contrast the natural gas grid only connects to an estimated $90 \%$ of all households in the UK - many rural areas do not have gas grid infrastructures - and rules on enabling new connections are more constrained in terms of the geography that is specified (within 23metres of a main pipeline) and the costs that can be charged. Whilst some assistance with these costs is provided to 'vulnerable customers' - such as older people and families with young children - there is a judgement being exercised here as to the degree to which access to natural gas should be enabled as a right for all, which is different to that for electricity. This distinction is historically embedded in the commitment of public funding to gas grid installation and extension, as well reflecting the alternatives to natural gas supply that are seen to be reasonably available (oil, propane, wood and similar).

Table 1: Rules of connection to electricity and gas grids in the UK

\begin{tabular}{|c|c|c|c|c|}
\hline & $\begin{array}{l}\text { Estimated \% } \\
\text { of } \\
\text { households } \\
\text { connected }\end{array}$ & Right of connection & Cost of connection & Differentiation \\
\hline Electricity & $100 \%$ & $\begin{array}{l}\text { Duty of distribution company } \\
\text { to connect when requested } \\
\text { (unless not reasonable to do } \\
\text { so) }\end{array}$ & $\begin{array}{l}\text { Any reasonable } \\
\text { expenses may be } \\
\text { charged to person } \\
\text { requesting }\end{array}$ & \\
\hline Gas & $90 \%$ & $\begin{array}{l}\text { Duty of distribution company } \\
\text { to connect if premises within } \\
23 \mathrm{~m} \text { of main pipeline }\end{array}$ & $\begin{array}{l}\text { All costs are } \\
\text { charged to person } \\
\text { requesting and they } \\
\text { may lay own pipe to } \\
\text { get within } 23 \mathrm{~m}\end{array}$ & $\begin{array}{l}\text { Ofgem 'assisted } \\
\text { gas connection' } \\
\text { scheme for } \\
\text { vulnerable } \\
\text { consumers }\end{array}$ \\
\hline
\end{tabular}

In addition to the geographic pattern and conditions of connection, matters of reliability, constancy and capacity can also be at issue in the specification of infrastructural systems that enable access. For example, for communities at the distant ends of spatially extended grid infrastructures, limitations on 
both reliability and capacity can be problematic and contentious, particularly when supply failures and constraints on the amount of energy that can be supplied (at any point in time) are evident.

Such considerations stress that the existence of an infrastructure of supply is only the starting point for the beneficial outcomes of energy use (and derivation of energy services) being realised as a right. This becomes even more apparent when questions of affordability are brought into view, moving into the territory of the 'right to use' energy.

Energy costs can be, or become, a significant proportion of peoples' everyday expenditure. In both Global South and North contexts the extent to which governments have a role in ensuring some degree of affordability and realised access to energy use, particularly for those on low incomes and/or vulnerable to the consequences of a lack of access to key energy services has been much debated. A number of particularly aspects of the terms and conditions of 'being a consumer' can become enrolled in such debates including:

- the terms of disconnection from supply infrastructures when bills are not paid

- methods of metering and paying for energy either before or after consumption

- $\quad$ the price per unit of energy and available tariff structures that can either penalise or enhance affordability for those on low incomes

- the cost of a basic level of 'necessary' or 'minimal' level of energy consumption compared to available incomes

- the social distribution of energy efficiency in terms of both the energy performance of buildings and energy using technologies, with impacts then on the amount of energy use necessary in order to derive energy services

Looking again to the example of the UK many of these aspects of the relationship between having access and being to able to make use of that access have been the focus of those campaigning and acting on behalf of the 'fuel poor' - including those recently working with the 'Energy Bill of Rights', referred to earlier, in order to lay down a set of demands to protect consumer interests. An increasingly developed and multi-faceted fuel poverty policy framework has been developed in the UK. For example, Table 2 shows both the legally required and voluntarily followed practices of energy companies related to disconnection of households from supply of electricity or gas infrastructures. A clear point at which the 'right to access energy' in effect breaks down at an individual level. 
Table 2: Rules applying to household disconnection from electricity and gas grids in the UK and voluntary policies followed by energy supply companies

\begin{tabular}{|c|c|c|c|}
\hline & Action 1 & Action 2 & Action 3 \\
\hline $\begin{array}{l}\text { All customers } \\
\text { (regulated) }\end{array}$ & $\begin{array}{l}\text { Try and agree a payment plan } \\
\text { the customer can afford }\end{array}$ & $\begin{array}{l}\text { Offer to install a prepayment } \\
\text { meter to enable consumer to } \\
\text { pay debt and avoid } \\
\text { disconnection }\end{array}$ & $\begin{array}{l}\text { Send a disconnection } \\
\text { notice } 7 \text { days before } \\
\text { disconnection }\end{array}$ \\
\hline $\begin{array}{l}\text { Vulnerable } \\
\text { Customers } \\
\text { (regulated) }\end{array}$ & $\begin{array}{l}\text { Distribution companies to } \\
\text { hold a Priority Services } \\
\text { Register (PSR). Listing: } \\
\text { old people; disabled; long } \\
\text { term ill health }\end{array}$ & $\begin{array}{l}\text { Those on PSR cannot be } \\
\text { disconnected between } 1^{\text {st }} \\
\text { October and } 31^{\text {st }} \text { March }\end{array}$ & \\
\hline $\begin{array}{l}\text { Energy UK } \\
\text { Safety Net } \\
\text { (voluntary) }\end{array}$ & $\begin{array}{l}\text { Never knowingly disconnect a } \\
\text { vulnerable customer at any } \\
\text { time of years }\end{array}$ & $\begin{array}{l}\text { Any customer found to be } \\
\text { vulnerable after } \\
\text { disconnection to be } \\
\text { reconnected }\end{array}$ & $\begin{array}{l}\text { Additional restrictions on } \\
\text { disconnection for } \\
\text { families with young } \\
\text { children }\end{array}$ \\
\hline
\end{tabular}

The staged process of moving through a series of steps to try and avoid a rapid and complete disconnection has been increasingly required of energy companies, and the category of vulnerable customers is again highlighted here as deserving of particular care and protection (particularly during the winter months, stressing the important of warmth as an energy service in the UK context). The pre-payment meter featuring in 'Action 2' has been particularly contentious in the UK, as whilst avoiding complete disconnection by the supplier, it still enables 'self-disconnection' by consumers if they have insufficient money to 'pre-pay' (Doble 2010). Whilst there are therefore mechanisms in place to try and limit disconnection of households from the grid energy infrastructures in the UK, this can and does still take place. This situation bares an interesting comparison with water where complete disconnection of households from the water supply is not now allowed in the UK, indicating that the right to water is in effect deemed to have a more vital and compelling basis than the right to energy, extending further into a universal 'right to use' rather than simply to have access.

A second example from the UK relates to the question of affordability. In defining 'fuel poverty' a comparison is made between the cost of the 'required energy' that needs to be consumed by a household with a defined measure of its affordability. If the cost of the 'required energy' is greater than the measure of affordability, then fuel poverty exists and policy measures are applied to try and address 
and ultimately eliminate this situation. The current definition applied since 2013 in England is that a household is in fuel poverty if:

"they have required fuel costs that are above average (the national median level) and were they to spend that amount, they would be left with a residual income below the official poverty line." (Department of Energy and Climate Change 2013)

A major recent review of fuel poverty policy in England (Hills 2013) argued that this approach to the definition of fuel poverty had "the key strength that it focuses on required, not actual, energy spend", The rationale is that this approach accounts for the fact that many fuel poor households will be under-heating their homes - their homes will be less warm than they really 'need' to be; and the need they really have would entail them spending more money on heating than they are able to without falling into significant debt. The notion of a standard 'heating regime' is therefore specified based on medical expertise as to what constitutes a safe room temperature. However, energy uses other than heating are also included in calculations of 'required energy' - energy for cooking, lighting, hot water, and appliances meaning that there is a basic minimum expectation of affordability related to a wider range of energy services. Rather than specifying a standard of energy service though, the required energy calculations for lighting, appliances, cooking and hot water each seek to reflect what is a typical or average level of household energy consumption (see Simcock and Walker 2015 for more detail). There is therefore an embedded the notion that people should be able to afford what is normal, they should be able to participate in everyday life (cooking, using hot water for showers and baths, watching TVs, running dishwashers) in a way that reflects current norms of energy use.

These two examples from the UK show that the notion of a right to energy can be extended a considerable way into questions of the conditions and affordability of use. In the UK political debate over the right to energy (refracted through a fuel poverty framing) did not therefore end when $100 \%$ connection of households to the electricity grid was enabled i.e. when a right of access was ensured. Over the past 30 years much else has been debated and many other claims have been made about the regulation of energy utilities, the protection of consumer interests and the needs in particular of vulnerable consumers. This is a process of debate and advocacy that is far from resolved and shows every sign of enduring for many years to come. 


\section{Conclusion}

In this paper I have opened up a series of questions about what it means to move from the broad rhetorical notion of a 'right to energy' into a more careful consideration of its definition and implementation. In so doing I have sought to fill out some of the political space within which questions of meaning, definition and specification will be and need to be debated. As with other rights, the right to energy once declared and supported is not simply available to be realised and implemented in an obvious and uncontentious manner. It is a complex right (again, as many others are) with that complexity beginning with the meaning of energy itself, through the conversion of energy into energy services (where the relation with well-being is in fact located), and into questions of access to supply infrastructure and the conditions and affordability of use. This opening up of what can be enrolled into (and excluded from) the notion of a right to energy means that it many ways it appears 'slippery', hard to pin down, with many alternative specifications available. There is also a distinct contingency to why energy use matters, what it is important for and to achieve, that means its normative and practical significance seemingly fluctuates, not the least with the variable relation between 'natural' and 'artificial' energy flows of heat and light.

All of this could be used to reject the notion of a right to energy at all. When faced with such a seemingly problematic process of specification and implementation, will there be an end-value in beginning with a rights claim? And does bringing this right into the UN framework of universal rights makes sense, when it appears necessarily situated in its significance and implications (and some argue it is already to some degree embedded within existing rights provisions: Tully 2006)? This line of deliberation raises broader questions that have been much debated about the value of rights declaration in and of themselves (Jones 1994; Attoh 2011). Some argue that embedding rights into legal frameworks can act as a smokescreen, giving the impression that something real has been achieved, when so much in fact rests on the details of specification and implementation in practice. Others point to the political value of pursuing rights claims, emphasising both the political power of rights language and the possibility of state and other actors being held to account through both political and potentially legal mechanisms.

Finding a way through these debates, for energy specifically, necessitates taking on board further tensions that revolve around the relation between the right to energy and the implications of energy use for both local environmental quality and the global climate. Both fossil-fuel based and nuclear energy systems raise deeply problematic environmental and climate justice issues at multiple scales (Walker 
2012, Bickerstaff et al 2013) and the conflict between competing justice claims are evidently at the core of global debates and negotiations about climate mitigation policy (as in Paris in December 2015). The right to energy is often quite rightly deployed by those in developing countries who argue that they need to develop their energy infrastructures and increase levels of energy consumption and carbon emissions in order to expand their economies and lift people out of poverty. This political deployment of the 'right to energy' is powerful and politically significant and makes it all the more crucial that much of what has been highlighted in this paper is carefully debated and considered. If the right to energy is taken to mean rolling out a fossil-fuel based and conventionally understood energy supply infrastructure across the world and sustaining the business models of incumbent energy interests then this will become deeply problematic for the global climate. There is clearly scope for such interests to organise behind the 'right to energy', finding value in its rhetorical power whilst be prepared to do very little to open up its realisation to modes of implementation that are more rather than less sustainable, inclusive and locally determined. As Bakker (2007) comments in critiquing the way that the right to water discourse has been co-opted by private companies:

"the adoption of human rights discourse by private companies indicates its limitations as an anti-privatization strategy ... 'rights talk' offer us an unimaginative language for thinking about new community economies .." (Bakker 2007)

Whilst such critique could be another argument for moving away from 'rights-talk' about energy, it can also be interpreted as a caution against withdrawing from debate and allowing the meaning and specification of the right to energy to be captured by incumbent interests. It is clear from the discussion in this paper that multiple, alternative ways of defining and realising the right to energy are available, and the space for political work that this paper has laid out can therefore be seen as opportunity for engagement over the normative qualities of future energy supply-demand configurations.

\section{References}

Attoh, K. A. (2011) What kind of right is the right to the city? Progress in Human Geography, 35(5), 669-685

Bafoil, F., F. Fodor, and D. Le Roux (2014), Acces a L'energie en Europe: Les Precaires Invisibles, Paris: Sciences Po Les Presses. 
Bakker, K (2007) The "Commons" Versus the "Commodity": alter-globalization, anti-privatization and the human right to water in the Global South, Antipode, 39(3), 430-455

Boardman, B. (2010) Fixing Fuel Poverty: Challenges and Solutions. London: Earthscan

Bickerstaff, K, Walker, G and Bulkeley, H. (2013) Energy Justice in a Changing Climate: Social Equity and Low Carbon Energy, Zed Books, London

Bradbrook, A and Gardam, J (2006) Placing access to energy services within a human rights framework, Human Rights Quarterly, 28(2), 389

Christman, B and Russell, H (2015) Readjusting the political thermostat: fuel poverty and human rights in the UK, Journal of Human Rights in the Commonwealth (forthcoming)

Department of Energy and Climate Change (2013) Fuel poverty statistics. Accessed 27/11/15 available at https://www.gov.uk/government/collections/fuel-poverty-statistics

Doble, M (2010) A Regulatory Policy for Self-disconnection: An Examination of the Reasons for and Implications of Pre-payment Meter Stoppages, Policy Studies, 21(3), 229-243

Freling, B (2012) Energy is a human right. Accessed 27/11/2015

http://www.bobfreling.com/2012/01/energy-is-a-human-right-the-hi.htm

Fuel Poverty Action (2015) Energy Bill of Rights. Accessed 27/11/2015

http://www.fuelpovertyaction.org.uk/home-alternative/energy-bill-of-rights-2/

Graham, C (2006) The politics of necessity: electricity and water in Great Britain, Journal of Consumer Culture, $29,435-448$

Hills, J. (2012) Final Report of the Fuel Poverty Review: getting the measure of fuel poverty, CASE report 72. London: Centre for Analysis of Social Exclusion, London School of Economics

Illich, I (1983) The Social Construction of Energy, paper presented at seminar held at El Colegio de Mexico, Mexico, July 1983. Available at http://landscapesofenergy.wikispaces.com/file/view/lllich Social+construction+of+Energy.pdf Jones, P (1994) Rights, Palgrave, Basingstoke 
Joy, K. J., Kulkarni, S., Roth, D and Zwarkeveen, M. (2014) Re-politicising water governance: exploring water re-allocations in terms of justice, Local Environment, 19(4), 954-973

Simcock, N. and Walker, G. (2015) Fuel Poverty Policy and Non-Heating Energy Uses. DEMAND Centre Working Paper 18. Lancaster: DEMAND Centre Lancaster University.

Sen, A. (2014) Global Warming Is Just One of Many Environmental Threats That Demand Our Attention, New Republic, August $23^{\text {rd }} 2014$. Available at:

https://newrepublic.com/article/118969/environmentalists-obsess-about-global-warming-ignore-poor-c ountries

Shove, E. and Walker, G. (2014) What is energy for?: energy demand and social practice Theory, Culture and Society, 31(5), 41-58

Sultana, F. and Loftus, A. (2013) The right to water: politics, governance and social struggles, Routledge: Abingdon

Tully, S. (2006) The Human Right to Access Electricity, Electricity Journal, 19(3), 30-39

Walker, G. (2012) Environmental Justice: concepts, evidence and politics, Routledge, Abingdon.

Walker, G. and Day, R. (2012) Fuel poverty as injustice: integrating distribution, recognition and procedure in the struggle for affordable warmth, Energy Policy, 49, 69-75

Walker, G. (2013) Inequality, sustainability and capability: locating justice in social practice in: Shove, E., Spurling, N. (Eds.), Sustainable Practices: Social Theory and Climate Change. Routledge, London. 